\title{
Evaluation of the Modulus of Elasticity in Damaged Wooden Beams
}

\author{
André Luis Christoforo ${ }^{1, *}$, Tulio Hallak Panzera ${ }^{2}$, Leandro José da Silva ${ }^{2}$, Victor Almeida de Araújo ${ }^{3}$, \\ Diogo Aparecido Lopes Silva ${ }^{4}$, Francisco Antonio Rocco Lahr ${ }^{5}$
}

\author{
${ }^{1}$ Centre for Innovation and Technology in Composites (CITeC), Department of Civil Engineering (DECiv), Federal University of São \\ Carlos (UFSCar), São Carlos, Brazil \\ ${ }^{2}$ Centre for Innovation and Technology in Composites (CITeC), Department of Mechanical Engineering, Federal University of São João \\ del-Rei, São João del-Rei, Brazil \\ ${ }^{3}$ Research Group LIGNO of UNESP-Itapeva, Department of Forest Sciences, School of Agriculture Luiz de Queiroz of University of São \\ Paulo (ESALQ/USP), Piracicaba, Brazil \\ ${ }^{4}$ Department of Production Engineering, Engineering School of São Carlos (EESC/USP), São Carlos, Brazil \\ ${ }^{5}$ Department of Structures Engineering (SET), Engineering School of São Carlos of University of São Paulo (EESC/USP), São Carlos, \\ Brazil
}

\begin{abstract}
This research aimed to employ two methods of calculation to obtain the bending modulus of elasticity in wooden specimens of Paricá (Shizolobium amazonicum), a simplified, adapted from the Brazilian standard ABNT NBR 7190, and another alternative based on the least squares method, in order to compare the efficiency of both. Therefore, some defects in wood specimens were created, based on the combination between the positions of the rips (damage) along the axis of the pieces $(8.63,17.25$ and $25.86 \mathrm{~cm})$ and their respective lengths $(5,10$ and $15 \mathrm{~mm})$, leading to a full factorial design of the type $3^{2}$, providing nine different combinations, apart from the reference condition (specimens without defects). The results of the confidence intervals revealed that the modulus of elasticity for both ways of calculation were equivalent for non-defective pieces, which did not occur with the inclusion of the defects in the specimens. In analysis of variance, the position, the length of the defects and the interaction between both proved to be not significant in the modulus of elasticity obtained from the methodology adapted from the Brazilian standard, which did not occur with the modulus of elasticity obtained from the least squares approach, proving to be more accurate than the simplified methodology, thus, emphasizing the importance of its use.
\end{abstract}

Keywords Stiffness, Bending, Least squares method, Design of experiments

\section{Introduction}

Among the main materials used in the manufacture of structures and structural parts, the wood is highlighted because of it is a renewable source of raw material and it presents an excellent resistance/weight ratio, becoming up to four times greater than steel [1]. Furthermore, contrary to the popular belief, the wood has good fire resistance when it is compared to steel.

With vast economic potential, the Amazon wood species of Paricá (Schizolobium amazonicum) has acquired more prominence among the reforested species in Brazil, insofar as it has increments in height and diameter which enable its use in few years [2].

The wooden structure project - as well as of other

* Corresponding author:

alchristoforo@yahoo.com.br (André Luis Christoforo)

Published online at http://journal.sapub.org/ijme

Copyright $\odot 2015$ Scientific \& Academic Publishing. All Rights Reserved materials - requires knowledge of some variables, such as the modulus of elasticity, obtained by non-destructive experimental tests, recommended by standard documents.

Brazilian standard NBR 7190:1997 (for wooden structures project) uses the structural model of static bending in three points to calculate the modulus of elasticity (Equation 1), restricted to the using of small-dimensions and defects-free specimens, even requiring the test of structural dimensions parts [3].

From Equation 1, $E_{s t}$ denotes the bending modulus of elasticity, $\Delta F\left(F_{50 \%}-F_{10 \%}\right)$ and $\Delta \delta\left(\delta_{50 \%}-\delta_{10 \%}\right)$ is the differences between forces and the displacements based on the maximum force obtained, $L$ is the distance between the support of bending test and $b$ and $h$ are respectively the measures of width and height of the cross section.

$$
E_{s t}=\frac{\Delta F \cdot L^{3}}{4 \cdot \Delta \delta \cdot b \cdot h^{3}}
$$

Alternatively for the calculation of the bending modulus of elasticity in parts with structural dimensions (Equation 2), 
[4] developed a methodology based on the least squares method applied to 18 pieces of Jatobá wood (Hymenaea $s p$ ), which presented the dimensions of $5 \times 5 \times 140$ centimeters, using the static bending test (Figure 1) in four points and three dial indicators - also named as "distance amplifying instruments".

From Equation 2, $\delta_{1}, \delta_{2}$ and $\delta_{3}$ correspond to the displacements measured respectively on the left, at the midpoint and on the right of this midpoint, $F$ is the applied force, $L$ is the distance between supports, and $b$ and $h$ is the width and height of the cross section.

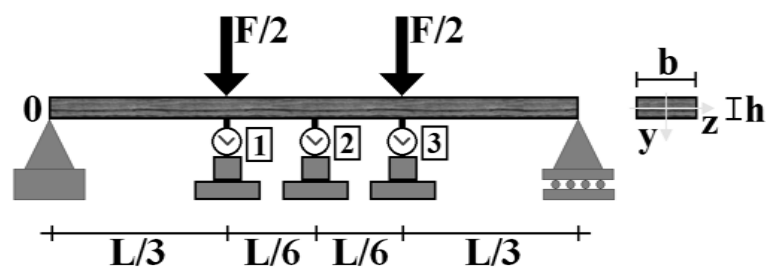

Figure 1. Model of test proposed for the calculation of the alternative modulus of elasticity $\left(E_{a l t}\right)$ Source: [4]

It is noteworthy that the displacement $\left(\delta_{2}\right)$ in the middle of the span $(L)$ in this research was limited to $L / 200$ proportion, which is a measure of small displacements used to check the serviceability limit state by the Brazilian standard [5], ensuring physical and geometric linearity to the tested pieces, denoting a nondestructive character to developed tests. The results were statistically equivalent between the modulus of elasticity obtained from both ways of calculation. However, the authors suggest the use of alternative methodology for each research developed to be more accurate when it is compared to the method adapted from the Brazilian standard.

$$
E_{\text {otm }}=\frac{443 \cdot F \cdot L^{3}}{36 \cdot\left(20 \cdot \gamma+23 \cdot \delta_{2}\right) \cdot b \cdot h^{3}}, \gamma=\delta_{1}+\delta_{3}
$$

In order to test of accuracy of the least squares methodology in the calculation of the modulus of elasticity, adapted from the study of [4] for the bending test at three points, defects were created in the wood pieces, and they are used to aforementioned method, along with the adapted Brazilian standard [5], allowing to check the sensitivity and

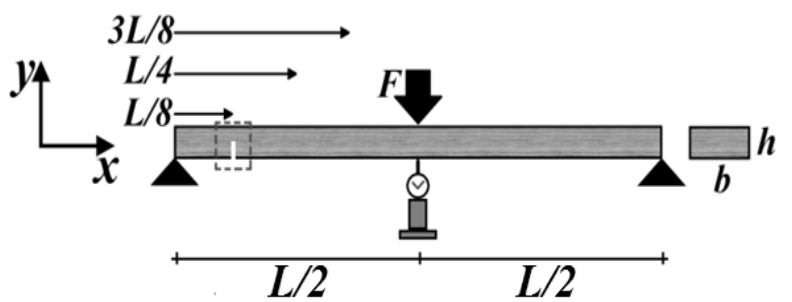

(a) precision, both in the determination of the bending stiffness.

\section{Material and Methods}

Figure 2 illustrates the structural model used to calculate the bending modulus of elasticity. From the theory of beams of Euler Bernoulli, the analytical displacements in the positions of the dial indicators 1, 2 and 3 (Figure 2b) are expressed by Equations 3 and 4, rewritten as function of the longitudinal modulus of elasticity $\left(\delta_{1}(E), \delta_{2}(E)\right.$ and $\left.\delta_{3}(E)\right)$.

$$
\begin{gathered}
\delta_{2}(E)=\delta_{\text {máx }}=\frac{1}{E} \cdot \frac{F \cdot L^{3}}{4 \cdot b \cdot h^{3}} \\
\delta_{1}(E)=\delta_{3}(E)=\frac{1}{E} \cdot \frac{11 \cdot F \cdot L^{3}}{64 \cdot b \cdot h^{3}}
\end{gathered}
$$

The modulus of elasticity to be calculated with the information from the testing model of Figure $2 b$ is related to the idea of least squares (Equation 5) [6-9], aiming to determine the value of modulus of elasticity for the waste generated between the values of analytic $\left(\delta_{i}(E)\right)$ and experimental $\left(\delta_{i}\right)$ displacements is minimized.

$$
f(E)=\frac{1}{2} \cdot \sum_{i=1}^{n}\left(\delta_{i}(E)-\delta_{i}\right)^{2}
$$

Substituting the Equations 3 and 4 in the Equation 5, and deriving and equating the latter to zero, it is achieved the effective modulus of elasticity $\left(E_{a l t}\right)$ for the structural scheme with three dial indicators, expressed by Equation 6, proving that it is the minimum and global point by the criterion of the second derivative.

$$
E_{\text {alt }}=\frac{249 \cdot F \cdot L^{3}}{32 \cdot \gamma \cdot b \cdot h^{3}}, \gamma=11 \cdot\left(\delta_{1}+\delta_{3}\right)+16 \cdot \delta_{2}
$$

Nine specimens of Paricá wood (Shizolobium amazonicum $)$ were used $(72 \times 4.5 \times 3.2 \mathrm{~cm})$ to obtain the modulus of elasticity according to two different ways of calculation (Equations 1 and 6).

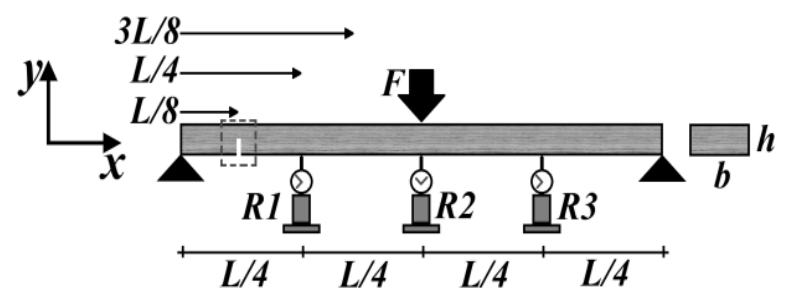

(b)

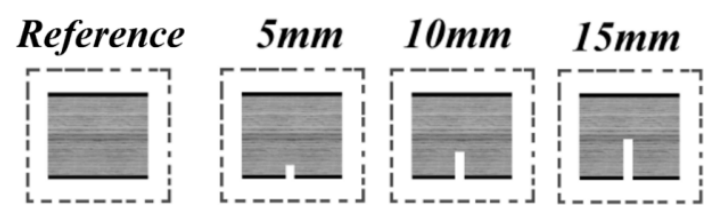

(c)

Figure 2. Conventional bending test (b), alternative (b) and length (depth) of the defects 
The relationship between effective length $(L=69 \mathrm{~cm})$ and the height of the section $(h=3,2 \mathrm{~cm})$ transverse $(L / h \geq 21)$ found in the study of [10] was maintained in the performing of the bending tests, allowing despise the effect of shear forces in the calculation of displacements, validating the use of the methodology proposed by the Brazilian standard [5] and the alternative methodology adapted of the study of [4] for obtaining the modulus of elasticity.

In order to investigate the accuracy of the alternative method (Equation 6) to obtain the modulus of elasticity in pieces with defects (Figure 2), along with this was used the Brazilian standard [5] (Equation 1).

The defects (Figure 2c) in the specimens were created from the combination between the positions of the rips (damages) along the axis of the pieces $(\mathrm{L} / 8=8.63 \mathrm{~cm}, \mathrm{~L} / 4=$ $17.25 \mathrm{~cm}$ and $3 \mathrm{~L} / 8=25.86 \mathrm{~cm}$ ) and of their respective lengths $(5,10$ and $15 \mathrm{~mm})$, leading to a complete factorial design of $3^{2}$, providing nine different combinations, explained in Table 1.

Table 1. Investigated experimental conditions

\begin{tabular}{ccc}
\hline $\begin{array}{c}\text { Experimental } \\
\text { Conditions }\end{array}$ & $\begin{array}{c}\text { Position in } \mathbf{X} \\
(\mathbf{c m})\end{array}$ & $\begin{array}{c}\text { Length in } \\
\mathbf{Y ( m m )}\end{array}$ \\
\hline C1 & 8.63 & 5 \\
C2 & 8.63 & 5 \\
C3 & 8.63 & 5 \\
C4 & 17.25 & 10 \\
C5 & 17.25 & 10 \\
C6 & 17.25 & 10 \\
C7 & 25.86 & 15 \\
C8 & 25.86 & 15 \\
C9 & 25.86 & 15 \\
\hline
\end{tabular}

The parts - three-to-three - were marked in the positions $\mathrm{L} / 8$ (pieces A1, A2 and A3), L/4 (B1, B2 and B3) and 3L/8 (C1, C2 and C3). Each of the nine non-defective specimens was tested in static bending. Subsequently, it was performed a groove on each of these specimens with a saw of $1.2 \mathrm{~mm}$ thickness, reaching $5 \mathrm{~mm}$ depth, and tested in static bending.

After the rips of $5 \mathrm{~mm}$, rips with $10 \mathrm{~mm}$ of total depth in the same specimens (A1, A2, $\cdots$, C2, C3) were realized, which were tested again in bending, ending with the insertion of the rips of $15 \mathrm{~mm}$ of depth, performing the last nine tests. Eighteen modulus of elasticity values of the non-defective pieces were obtained, as well as 9 values from the adapted methodology of the Brazilian standard, and other values from the alternative methodology. In relation to defective pieces, 27 values of the modulus of elasticity through the usual methodology were obtained, as well as other 27 values by the alternative method.

The equation to calculate the modulus of elasticity according to Brazilian standard [5] uses the values of the difference between forces $\left(\Delta F=F_{50 \%}-F_{10 \%}\right)$ and displacements $\left(\Delta \delta=\delta_{50 \%}-\delta_{10 \%}\right)$ based on maximum strength, and are replaced by the values of the difference between forces $\left(\Delta F=F_{L 2 / 00}-F_{L / 400}\right)$ and displacements $\left(\Delta \delta=\delta_{L / 200^{-}}\right.$ $\left.\delta_{L / 400}\right)$ concerning to the displacements $L / 400$ and $L / 200$, where $L / 400$ is an inferior measure to the limit presented by the Brazilian standard. These values of the difference between forces and displacements were also used to calculate the modulus of elasticity according to the alternative approach.

To verify the accuracy of the calculation of the modulus of elasticity of the alternative approach opposite the adapted methodology of the Brazilian standard, it was initially used a hypothesis test ( $t$ test) comparing the modulus of elasticity merely of the non-defective pieces, in order to check, even as found in the study of [4], the equivalence between both studies. In sequence, the hypothesis test was used, confronting all the values of the modulus of elasticity by the two ways of calculation aforementioned. Checked the non-equivalence among the modulus of elasticity, coming from the nine experimental conditions stipulated to the factorial design, these values were estimated using the analysis of variance (ANOVA) through the software Minitab $^{\circledR}$ version 14, enabling to determine the influence of each factor (position in $\mathrm{X}$ and length in $\mathrm{Y}$ of the defects), as well as the interaction between them in the calculation of the stiffness by the two presented methodologies. When the significance of individual factors or interaction between them by ANOVA was verified, and in sequence, multiple comparison test of Tukey was used. The hypothesis test was evaluated for a significance level $(\alpha)$ of $5 \%$, using as the null hypothesis $\left(\mathrm{H}_{0}\right)$ and equivalence among means, and the non-equivalence as alternative hypothesis $\left(\mathrm{H}_{1}\right)$. P-value higher than the significance level (0.05) implies to accept the null hypothesis, refuting it otherwise.

For ANOVA, at $5 \%$ of significance level, the formulated null hypothesis took on the equivalence of means among the treatments, and the non-equivalence (at least one among the treatments) as an alternative hypothesis. P-value higher than the significance level implies to accept the null hypothesis, rejecting it otherwise.

For data normality - required item for the hypothesis test and analysis of variance - was used the Anderson-Darling test, and for the verification of the homogeneity of variances, the tests of Bartlett and Levene were used, completing to validate the model of ANOVA.

For the Anderson-Darling test, at a significance level of $5 \%$, the formulated null hypothesis was to be normal to the data distribution, and the non-normality of the data as an alternative hypothesis. Thus, P-value of the test higher than the significance level implies to accept $\mathrm{H}_{0}$, rejecting it otherwise. For Barlett and Levene tests, also with $5 \%$ of significance level, the formulated null hypothesis was the equivalence of variances, and non-equivalence for the alternative hypothesis. Thus, P-value of the test higher than the significance level implies to accept the null hypothesis, rejecting it otherwise. 


\section{Results and Discussions}

Table 2 shows the results of the modulus of elasticity of the pieces with and without defects $(5,10$ and $15 \mathrm{~mm})$, where $\bar{x}$ is the sample mean, $S d$ is the standard deviation, $C v$ is the coefficient variation and Min and Max the lowest and highest values found in the study.

Table 2. Modulus of elasticity

\begin{tabular}{|c|c|c|}
\hline \multicolumn{3}{|c|}{ Without defect } \\
\hline Statistics & $\mathrm{E}_{\mathrm{st}}(\mathrm{MPa})$ & $\mathbf{E}_{\text {alt }}(\mathrm{MPa})$ \\
\hline $\bar{x}$ & 7705 & 8613 \\
\hline$S d$ & 993 & 1199 \\
\hline$C v$ & 13 & 14 \\
\hline Min & 6716 & 7599 \\
\hline Máx & 9438 & 9547 \\
\hline \multicolumn{3}{|c|}{ Defect in $5 \mathrm{~mm}$} \\
\hline Statistics & $\mathrm{E}_{\text {st }}(\mathrm{MPa})$ & $\mathrm{E}_{\text {alt }}$ (MPa) \\
\hline $\bar{x}$ & 7666 & 7213 \\
\hline$S d$ & 1115 & 1080 \\
\hline$C v$ & 15 & 15 \\
\hline Min & 6519 & 6010 \\
\hline Máx & 9345 & 8750 \\
\hline \multicolumn{3}{|c|}{ Defect in $10 \mathrm{~mm}$} \\
\hline Statistics & $\mathrm{E}_{\mathrm{st}}(\mathrm{MPa})$ & $\mathrm{E}_{\text {alt }}(\mathrm{MPa})$ \\
\hline $\bar{x}$ & 6941 & 6817 \\
\hline$S d$ & 1048 & 1032 \\
\hline$C v$ & 15 & 15 \\
\hline Min & 5853 & 5927 \\
\hline Máx & 8787 & 8672 \\
\hline \multicolumn{3}{|c|}{ Defect in $15 \mathrm{~mm}$} \\
\hline Statistics & $\mathrm{E}_{\mathrm{st}}(\mathrm{MPa})$ & $\mathbf{E}_{\text {alt }}(\mathrm{MPa})$ \\
\hline $\bar{x}$ & 6441 & 6316 \\
\hline$S d$ & 1128 & 1055 \\
\hline$C v$ & 18 & 17 \\
\hline Min & 4990 & 5004 \\
\hline Máx & 8443 & 8235 \\
\hline
\end{tabular}

Table 3 presents the results of the confidence interval $(\mu)$ between the modulus of elasticity $\left(\mathrm{E}_{\mathrm{st}}, \mathrm{E}_{\text {alt }}\right)$ obtained among all the pieces without defects and among all the obtained results (with and without defects). Comparing the results of the modulus of elasticity of both ways of calculation for the pieces without defect, the statistical equivalence between them (P-valor $>0.05$ ) was verified. This situation did not occur in the inclusion of the obtained results of the pieces with defect $\mathrm{P}$-valor $<0.05$ ), evincing that they are different.

Table 4 shows the ANOVA results for the modulus of elasticity, where $\mathrm{X}^{*} \mathrm{Y}$ is the interaction among the factors (position in $\mathrm{X}$, length in $\mathrm{Y}$ of the caused defects), and $\mathrm{DF}$ is the degress of freedom. Significant P-values $(<0.05)$ in the ANOVA are underlined in Table 4.

Table 3. Results of the confidence interval

\begin{tabular}{ccccc} 
& DF & P-value & IC $(\boldsymbol{\mu})$ & Condition \\
\hline $\begin{array}{c}\text { Non-defective } \\
\left(\mathrm{E}_{\mathrm{st}}, \mathrm{E}_{\mathrm{alt}}\right)\end{array}$ & 15 & 0.106 & $\begin{array}{c}-315.5 \leq \mu \leq \\
198.3\end{array}$ & Equivalent \\
With and & & & $558.1 \leq \mu \leq$ & \\
$\begin{array}{c}\text { without defect } \\
\left(\mathrm{E}_{\mathrm{st}}, \mathrm{E}_{\mathrm{alt}}\right)\end{array}$ & 57 & 0.003 & 771.0 & Non-equivalent \\
\hline
\end{tabular}

Table 4. Results of ANOVA for the modulus of elasticity

\begin{tabular}{ccccc}
\hline Modulus & DF & Position in $\mathbf{X}$ & Length in $\mathbf{Y}$ & $\mathbf{X} * \mathbf{Y}$ \\
\hline $\mathrm{E}_{\mathrm{st}}$ & 26 & 0.321 & 0.154 & 0.986 \\
$\mathrm{E}_{\text {alt }}$ & 26 & $\underline{0.017}$ & $\underline{0.000}$ & 0.236 \\
\hline
\end{tabular}

Figure 3 shows the results of the Anderson-Darling test and of Bartlett and Levene for the modulus of elasticity, verifying the normality in the distribution and the equivalence in variances by $\mathrm{P}$-values higher than the significance levels of the tests (5\%), validating the obtained results of the confidence interval ( $t$ Test) and ANOVA.

From Table 4 it is verified that the factors and the interaction between them were not significant in the modulus of elasticity obtained in accordance with the prescriptions of the Brazilian standard to $\left(\mathrm{E}_{\mathrm{st}}\right)$, fact that did not occur with the alternative modulus of elasticity, which had their values affected by two investigated values (without interaction effects), evincing the sensitivity and higher precision of the alternative approach opposite to adapted method of the Brazilian standard.

Table 5 presents the results of the Tukey test of the significant factors by ANOVA on the values of modulus of elasticity of the alternative approach. Similar letters imply in groups with equivalent means.

Table 5. Results of Tukey test for the alternative modulus of elasticity

\begin{tabular}{ccccccc} 
& \multicolumn{6}{c}{ Factors } \\
\cline { 2 - 7 } & \multicolumn{3}{c}{ Positions in $\mathbf{X}$} & \multicolumn{4}{c}{ Lengths in Y (mm) } \\
\cline { 2 - 8 } & L/8 & L/4 & $\mathbf{3 L / 8}$ & $\mathbf{5}$ & $\mathbf{1 0}$ & $\mathbf{1 5}$ \\
$\bar{x}$ & 7415 & 7130 & 6850 & 6240 & 5980 & 5620 \\
Groups & A & B & B & A & A & B \\
\hline
\end{tabular}

From the results presented in Table 5 , it is verified that the positions of the defects $\mathrm{L} / 4$ and $3 \mathrm{~L} / 8$ led to equivalent values for the alternative modulus of elasticity, however, significantly lower than values of $E_{\text {alt }}$ obtained with the position of the defect closer the support (L/8), and with regard to the influence of the defect length, it was found a significance in the modulus of elasticity solely for the $15 \mathrm{~mm}$, which was the biggest defect caused in the test specimens. 


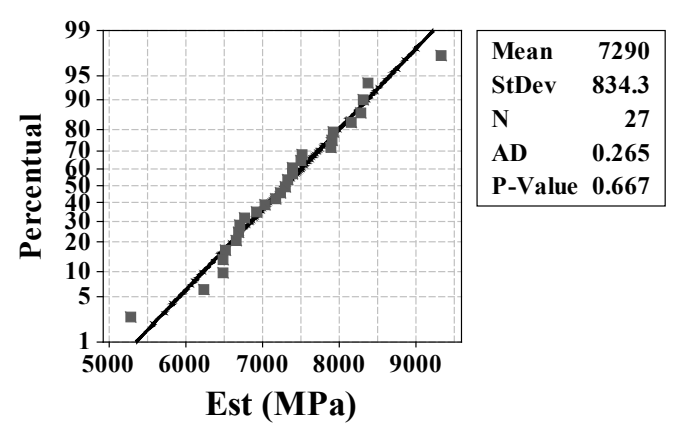

(a)

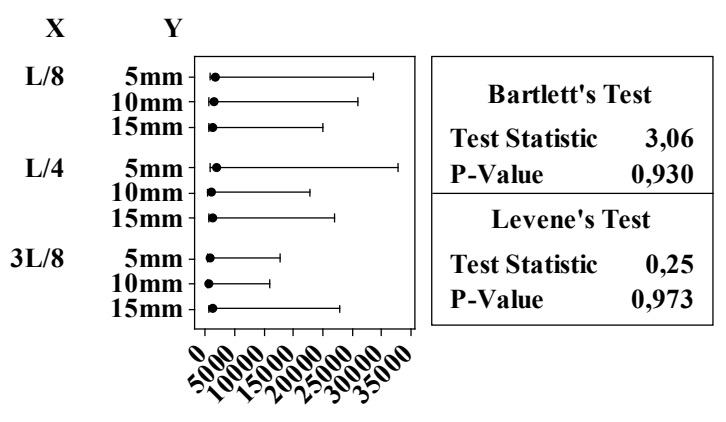

Confidence Interval of Bonferroni [95\%] - Est

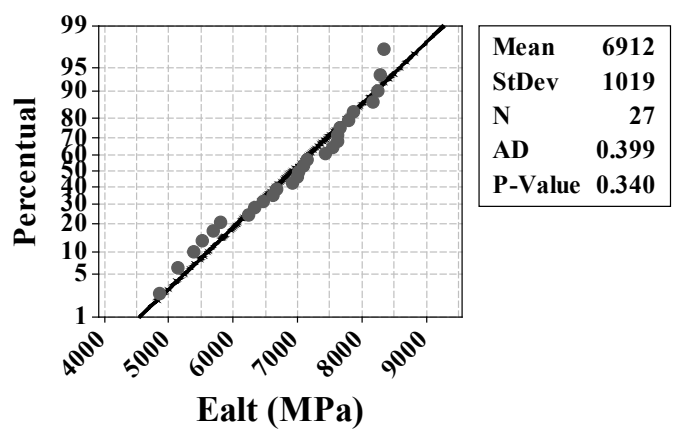

(b)

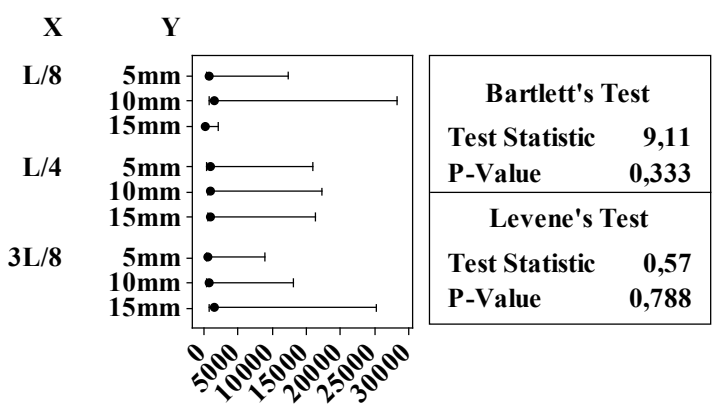

Confidence Interval of Bonferroni [95\%] - Ealt

(d)

Figure 3. Results of the test of normality $(a ; b)$ and equivalence among variances (c; d) of the modulus of elasticity $E_{\text {st }}$ and $E_{\text {alt }}$

\section{Conclusions}

For the factors and experimental levels investigated in this study "positions and lengths of the caused defects", the methodology alternative used in the calculation of the bending modulus of elasticity showed significantly different results from those of Brazilian standard adaptation [5]. Thus, the methodology for the modulus of elasticity calculation is more accurate and reliable when it is compared to the equation for stiffness calculation through Brazilian standard (among other standard documents), evincing the importance of their use, primarily, in parts with structural dimensions, because of the higher possibility of the existence of internal defects in the material.

Whereas methods of non-destructive test are used in the classification of structural parts, it should be suggest, as reference for comparisons with the results of the tests with transverse vibration and ultrasound equipments, the use of the methodology proposed in this paper.

\section{REFERENCES}

[1] Calil, C. Jr.; Lahr, F. A. R.; Dias, A. A. Dimensionamento de elementos estruturais de madeira. Editora Manole Ltda., Barueri - SP, ISBN: 85-204-1515-6, 2003.

[2] Almeida, D. H.; Scaliante, R. M.; Macedo, L. B.; Macêdo, A.
N.; Dias, A. A.; Christoforo, A. L.; Calil Junior, C. Caracterização completa da madeira da espécie amazônica paricá (Schizolobium amazonicum Herb) em peças de dimensões estruturais. Revista Árvore, v. 37, n. 6, p. 1175-1181, 2013.

[3] Christoforo, A. L.; Panzera, T. H.; Batista, F. B.; Borges, P. H.; Rocco, F. A. L. Numerical evaluation of the longitudinal modulus of elasticity in structural round timber elements of the Eucalyptus genus. Revista Brasileira de Engenharia Agrícola - SBEA, v. 31, p. 1007-1014, 2011.

[4] Christoforo, A. L.; Ribeiro Filho, S. L. M.; Wolenski, A. R. V.; Borges, A. R.; Rocco, F. A. L.; Demarzo, M. A. Determinação do Módulo de Elasticidade em Vigas Estruturais de Madeira pelo Método dos Mínimos Quadrados. Vértices (Campos dos Goitacazes), v. 14, p. 61-70, 2012.

[5] Associação Brasileira de Normas Técnicas (ABNT). NBR 7190. Projeto de Estruturas de Madeira. Rio de Janeiro Brazil, 1997.

[6] Christoforo, A. L.; Panzera, T. H.; Silva, D. A. L.; Fiorelli, J.; Rocco, F. A. L. Shear and Longitudinal Modulus of Elasticity in Structural Lumber Beams. International Journal of Materials Engineering, v. 4, p. 31-36, 2014.

[7] Christoforo, A. L.; Lahr, F. A. R.; Valarelli, I. D.; Battistelle, R. A. G.; Branco, L. A. M. N.; Chahud, E.; Panzera, T. H. Evaluation of the Tensile Modulus of Elasticity in Parallel Direction to the Grain for Eucalyptus grandis Wood Specie. Advanced Materials Research (Online), v. 1088, p. 599-602, 2015.

[8] Christoforo, A. L.; Panzera, T. H.; Calil Neto, C.; Demarzo, 
M. A.; Ribeiro Filho, S. L.M.; Toniolo, L. E.; Amstalden, R.; Rocco, F. A. L. Alternative methodology for calculating the modulus of elasticity of wooden beams of structural dimensions. Engenharia Agrícola (Impresso), v. 34, p. 153-160, 2014.

[9] Varanda, L. D.; Christoforo, A. L.; Almeida, D. H.; Silva, D. A. L.; Panzera, T. H.; Rocco, F. A. L. Evaluation of modulus of elasticity in static bending of particleboards manufactured with Eucalyptus grandis wood and oat hulls. Acta Scientiarum. Technology (Online), v. 36, p. 405-411, 2014.

[10] Rocco Lahr, F. A. Sobre a determinação de propriedades de elasticidade da madeira. 216 p., 1983. Tese (Doutorado) em Engenharia de Estruturas). Departamento de Engenharia de Estruturas. Escola de Engenharia de São Carlos da Universidade de São Paulo (EESC/USP), São Carlos - Brazil, 1983. 